\author{
Military Technical College \\ Kobry El-Kobbah, \\ Cairo, Egypt.
}

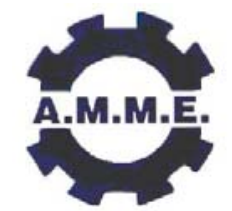

\title{
DRY SLIDING WEAR BEHAVIOR OF NANO and MICRON PARTICLES REINFORCED P/M BASED METAL MATRIX COMPOSITES
}

\author{
VENKATESWARAN* K., M. KAMARAJ* M. and PRASAD RAO* K.
}

\begin{abstract}
Powder Metallurgy (P/M) based Metal Matrix Composites (MMCs) has emerged as a class of materials capable of advanced structural, aerospace and automotive applications in recent years. In spite of various process and property advantages, they have one major disadvantage namely poor wear resistance. This restricts the use of these MMCs, for wear resistant applications. Use of reinforcement of ceramic hard particles namely $\mathrm{SiC}$ and $\mathrm{Al}_{2} \mathrm{O}_{3}$, to improve wear properties in MMCs are common in spite of its high cost and poor compatibility with base metal matrix. Recently, interest in use of intermetallic particles in MMCs for tribological applications has grown significantly. The principal advantage of intermetallic composites is the metal-like properties of the matrix. Also, they are attractive in tribological applications not only for their intrinsic properties such as hardness, stability, wear resistance etc. but also because of their compatibility with metallic matrices. Hence, the present investigation aims at studying the influence of mechanically alloyed nano iron aluminide intermetallic particles and micron alumina ceramic particles on the wear behavior of P/M based SS316L metal matrix composites were studied using a pin-on-disk wear testing machine under dry sliding condition. Both, iron aluminide and alumina were used as particle reinforcement with 10 and $20 \%$ volume in the matrix. The composites were prepared by mixing and cold compacting followed by sintering SS316 $\mathrm{L}$ at $1250^{\circ} \mathrm{C}$. The presence and distribution of $\mathrm{Fe}_{3} \mathrm{Al}$ and $\mathrm{Al}_{2} \mathrm{O}_{3}$ phases on the matrix were identified. The experimental results indicated improvement in dry sliding wear properties of MMCs compared to their plain alloys. It also revealed that unreinforced SS316L showed lower wear resistance, while the composites with $\mathrm{Fe}_{3} \mathrm{Al}$ were found superior during longer sliding conditions. Alumina reinforced SS316L based MMCs impart good wear resistance only, for shorter sliding distances and the beneficial effects of $\mathrm{Al}_{2} \mathrm{O}_{3}$ tend to decrease as the sliding distance increases. Wear tracks were characterized by SEM techniques to identify the possible wear mechanisms for the composites studied.
\end{abstract}

* Department of Metallurgical and Materials Engineering, Indian Institute of Technology Madras, Chennai 600 036, India. Email: kamaraj@iitm.ac.in. 


\section{INTRODUCTION}

Powder metallurgy based ferrous and nonferrous components find applications in automobile, household appliances and electrical motor industries [1]. They combine the advantages of low weight and self-lubrication under service conditions. Of all these properties, self lubrication, in particular, enables them to be considered for bearing applications in general. But, when considering the use of structural components such as gears, levers etc. for applications, good wear resistance under severe service conditions is expected. In such critical wear applications, improved wear resistance of the alloy becomes imperative. Hence, there is a need to improve the wear properties of the P/M based ferrous and nonferrous alloys, specifically under severe dry sliding conditions where lubrication failure is anticipated during service. Use of reinforcement of ceramic hard particles namely $\mathrm{SiC}$ and $\mathrm{Al}_{2} \mathrm{O}_{3}$, to improve wear properties in MMCs are common in spite of its high cost and poor compatibility with base metal matrix. Recently, interest in use of intermetallic particles in MMCs for tribological applications has grown significantly. The principal advantage of intermetallics is the metal-like properties of the intermetallics as particle reinforcement in the matrix. Also, they are attractive in tribological applications not only for their intrinsic properties such as hardness, stability, wear resistance etc. but also because of their compatibility with metallic matrices. Also, in literature, it is reported that introduction of intermetallic phases in metal-matrix composites improves its dry wear performances [2].

For these matrices, among the various intermetallics, iron aluminides can become an alternative for the other reinforcing materials considering their high strength, high stability, good oxidation resistance, low density and good wear resistance. Iron aluminides are particularly suitable from the raw materials cost point-of-view because they consist primarily of abundant and inexpensive elements (iron and aluminum). Hence, Iron aluminides have been considered for a variety of their applications [3].

In the past decades, mechanical alloying (MA), in particular, high energy ball milling has been highly developed and widely applied to prepare various materials after the development of oxide dispersion strengthened alloys by Benjamine [4]. Mechanical alloying produces iron aluminide powders of consistent quality with homogenous distributed products [5].

SS316L based powder metallurgy components are being considered nowadays for automobile industries, due to its excellent corrosion properties. At the same time, consideration of SS316L for wear based applications such as levers, gears etc is very limited because they exhibit poor wear resistance during applications. Hence a need arises to improve the wear resistance of P/M based SS316L systems. If improved, this will attract the designers of automobile components to consider sintered SS316L.

Wear tests conducted on P/M based SS316L MMCs with TiAl intermetallic as reinforcement particles up to 377 meters with various volume fractions $(3,6$ and $9 \%)$ revealed that wear behavior of SS316 had improved when TiAl reinforcement was added. Overall improvement in hardness in the matrix was observed during sliding and abrasive wear was observed [6]. Similar studies conducted on SS304 MMCs with 20 vol. \% $\mathrm{TiB}_{2}$ intermetallics up to 2500 meters of sliding distance showed improved wear properties during sliding. 
Powder metallurgy technology offers the advantage of net-shaped consolidation at competitive cost with expected combination of properties like wear resistance and better self-lubrication. Generally, powder metallurgy parts possess low wear resistance compared to ingot materials due to its inherent porosity and hence improvement of wear properties is to be explored. Wear studies conducted on $\mathrm{Fe}_{3} \mathrm{Al}$ based alloy castings revealed that they perform well under severe tribological conditions [6]. Also, studies conducted by Alman et.al [3] revealed the improvement of erosion resistance on composites by adding $\mathrm{Fe}_{3} \mathrm{Al}$ alloys. Also, comparison of wear properties of $\mathrm{Fe}_{3} \mathrm{Al}$ reinforcements with that of a known ceramics namely $\mathrm{Al}_{2} \mathrm{O}_{3}$ is needed to evaluate and compare if at all intermetallics are to be considered for tribological applications. Hence, the present investigation aims at studying the influence of mechanically alloyed $\mathrm{Fe}_{3} \mathrm{Al}$ and $\mathrm{Al}_{2} \mathrm{O}_{3}$ particle reinforcement on the dry sliding wear properties, on P/M- SS316L based MMCs.

\section{EXPERIMENTAL DETAILS}

\section{Preparation of $\mathrm{Fe}_{3} \mathrm{Al}$ Powders by Mechanical Alloying}

In the mechanical alloying process, a Fritsch P5 planetary mill was used. The ball-topowder weight ratio (BPR) is 5:1. Pure iron and aluminum powders were used as the starting materials. The specification of elementary powders and initial powder mixture is shown in Table 1. Powder mixtures were mechanically alloyed for 40 hours. Mechanically alloyed samples were characterized by X-Ray Diffraction analysis and a typical intensity pattern is shown in Fig 1 which confirmed the formation of iron aluminide. The mechanically alloyed iron aluminide particles were characterized by TEM (Fig. 2 a) and SEM (Fig.2 b) and the particles were in nano size ranges (16-25 nm) with near spherical shape. The alumina partic' $\mathrm{s}$ used for particle reinforcement was in the size range of 1 micron.

\section{Preparation of Metal Matrix Composites}

Metal matrix composites mixture was prepared by using SS316L powders with $\mathrm{Fe}_{3} \mathrm{Al}$ and $\mathrm{Al}_{2} \mathrm{O}_{3}$ powders under two volume fractions namely $10 \%$ and $20 \%$. The mixing was carried out in the Fritsch P5 planetary mill at $100 \mathrm{rpm}$ for 30 minutes.

\section{Powder Compaction and Sintering}

The mixtures were uniaxially compacted at $600 \mathrm{MPa}$ in the form of cylindrical pin samples of diameter $10 \mathrm{~mm}$ and length $15 \mathrm{~mm}$. The green compacts were sintered at $1250^{\circ} \mathrm{C}$ for 30 minutes in $90 \%$ nitrogen and $10 \%$ hydrogen mixtures. The density of the component was maintained at $6.6 \mathrm{~g} / \mathrm{cc}$. The sintered MMCs compacts were studied under optical microscope. Fig. 3 shows the presence of pores and austenitic phases in the unreinforced iron matrix. The closure of pores due to the presence of $\mathrm{Fe}_{3} \mathrm{Al}$ and $\mathrm{Al}_{2} \mathrm{O}_{3}$ particles is clearly evident from Figs. $4-5$ respectively. It is also understood that the distribution of $\mathrm{Fe}_{3} \mathrm{Al}$ and $\mathrm{Al}_{2} \mathrm{O}_{3}$ particles are depending on the volume fractions considered during processing of MMCs. Also, the distribution was found to be higher in higher volume fractions namely in $20 \%$ compared to $10 \%$. 
Table 1: Specification of powders

\begin{tabular}{|c|c|c|}
\hline & Fe powder & Al powder \\
\hline Size (mesh) & $\begin{array}{c}-100+325 \text { mesh } 82 \% \\
-325 \text { mesh } 14 \% \\
-80+100 \text { mesh } 3.7 \%\end{array}$ & -200 mesh \\
\hline $\begin{array}{c}\text { Composition of } \\
\text { mixture (vol.\%) }\end{array}$ & 70 & 30 \\
\hline
\end{tabular}

\section{Dry Sliding Wear Studies}

The wear behavior of the reinforced and unreinforced MMCs was evaluated through a pin-on-disc test as per ASTM Standard G99 under dry sliding conditions. Wear test prerequisites including sample surface polishing and cleaning were carried out. Pin specimens were made to slide against alloy steel disc of hardness $62 \mathrm{HRC}$ at a constant load of $20 \mathrm{~N}$ and $40 \mathrm{~N}$ up to the sliding distance of $6480 \mathrm{~m}$. Wear resistance was determined by measuring the weight loss of the specimen after each sliding distance $2160,3240,4320$ and $6480 \mathrm{~m}$. The wear tracks were examined using Scanning Electron Microscope (SEM), JEOL model JSM - 840 A.

\section{RESULTS AND DISCUSSIONS}

\section{Wear Behavior}

Wear test results for unreinforced and reinforced SS 316L based MMCs are presented in Fig.6. From Fig.6 it can be seen that the wear loss was found to be increasing with sliding distance whereas the wear rate was found to decrease with sliding distance in both SS316L matrix and SS316 with 10 and $20 \% \mathrm{Fe}_{3} \mathrm{Al}$ matrix. In fact, there was a reduction in the wear rate from $21 \times 10^{-13} \mathrm{~m}^{3} / \mathrm{m}$ to $9.85 \times 10^{-13} \mathrm{~m}^{3} / \mathrm{m}$ (by $50 \%$ ), with $20 \%$ addition of $\mathrm{Fe}_{3} \mathrm{Al}$ to the matrix. In $10 \% \mathrm{MMC}$, wear rate is reduced by $38 \%$ at $20 \mathrm{~N}$ load and by $49 \%$ at $40 \mathrm{~N}$. Similarly, reduction in the wear rate in $20 \%$ MMC with sliding distance was observed for $20 \mathrm{~N}$ and $40 \mathrm{~N}$ loads. This clearly explains the influence of iron aluminide on the wear properties of the SS316L matrix. There was a significant reduction in the weight loss up to about $50 \%$ due to the addition of the iron aluminide in the matrix. It is evident that iron aluminide particles have great influence on the wear behavior of the iron based MMCs.

The improved wear resistance may be attributed to the combined effect of volume fraction of the intermetallic particles as well as the intrinsic work hardening characteristics of the iron aluminide [7]. The size of iron aluminide particles used in the matrix was of the order of 16-25 nano meters. As the nano particles occupy the pores, they not only close the pores but also strengthen the matrix by particle reinforcement. The hardness values of $10 \%$ and $20 \%$ MMCs were measured to be $715 \mathrm{HV}_{0.10}$ and $885 \mathrm{HV}_{0.10}$ respectively which are very much higher than the matrix hardness value of $400 \mathrm{HV}_{0.10}$.

Hence, the combined effect of increase in the hardness of the matrix and matrix strengthening by the nano particle reinforcement is responsible for the improved the wear behavior of the matrix compared to unreinforced matrix. Since, iron aluminide 
intermetallic particles possess metal like structure, the material can plastically deform simultaneously maintaining the hardness. This can result in decreasing the wear with higher volume fraction of the particle reinforcements. Also, the work hardening of base SS316 L matrix with high rate of work hardening of iron aluminide particles during sliding contributed for the improvement of wear properties of the SS316L matrix with iron aluminide particles.

However, in case of alumina-based matrix, an increasing trend of both wear loss and wear rate with respect to sliding distances were noticed and the effect was pronounced especially at longer sliding distances. As for as SS316L matrix was concerned, the alumina particle reinforcement did not impart beneficial wear properties as a whole. In fact the wear rate increased from $21 \times 10^{-13} \mathrm{~m}^{3} / \mathrm{m}$ to $55 \times 10^{-13} \mathrm{~m}^{3} / \mathrm{m}$ (SS316L to SS316 L with $20 \%$ alumina) at longer sliding distances of 6480 meters. This observation indicates that the alumina reinforcement in SS316L may not be suitable for longer duration of service.

During sliding, MML formation was observed on the worn surfaces in $\mathrm{Fe}_{3} \mathrm{Al}$ based SS316L MMCs (Fig.7). Since, base matrix SS316 L was resistant to oxidation, examination of worn surface revealed that MML was absent during sliding. Hence, the observed MML must have been contributed by $\mathrm{Fe}_{3} \mathrm{Al}$ particle reinforcement. Also, the absence of MML formation during sliding confirms the high wear rates observed during studies for the unreinforced MMCs.

When iron aluminide particle slides against the $\mathrm{HCHCr}$ (high carbon and high Chromium) counter disc, due to dry sliding conditions, the temperature on the particles could rise due to friction. This temperature rise can promote tribo chemical reactions in the iron aluminide debris from the matrix during sliding. Iron aluminide debris gets converted to $\mathrm{Fe}_{2} \mathrm{O}_{3}$ and $\mathrm{Al}_{2} \mathrm{O}_{3}$ and forms a mixture of oxide layers. This surface-oxide layer, in the repetitive reciprocal sliding, protects the surface from severe wear [8]. Though formation of this oxide layer depends on the volume $\%$ of $\mathrm{Fe}_{3} \mathrm{Al}$ in the matrix, this layer along with the wear debris from the base SS316L matrix forms a mixed tribo layer. This layer further protects the surface from severe wear. MML and delamination was more extensively observed in $20 \%$ MMC compared to $10 \%$ matrix at $6480 \mathrm{~m}$ of sliding, as shown in Fig.9. This was due to higher percentage of iron aluminide present in case of $20 \%$ matrix.

The average $\mu$ values falls in the range of $0.5-0.6$. This was observed by Hsu et al, (9) also, in their studies on austenitic stainless steels. The drop and recover events noticed in $\mu$ values were associated with the generation of debris particles during the sliding process.

Porosity effects and size of the iron aluminide particles should also be taken into account when considering the wear behavior. Since, particle size of $\mathrm{Fe}_{3} \mathrm{Al}$ was in nanometers, particles can easily occupy the pores and close the pores (Fig.9). Closure of pores prevents the formation of the cracks from pores which is detrimental for wear resistance of the MMCs. Porosity measurements using image analyzer revealed porosity levels of 10, 8.1 and 7.2 respectively for SS316L, $10 \%$ and $20 \%$ MMCs. The reduction in porosity in MMCs reflects in the reduction in wear rates of reinforced MMCs with $\mathrm{Fe}_{3} \mathrm{Al}$. The reduction in porosity levels also improves the overall matrix strength, hardness and control of wear damages in the initial sliding distances. 
Hence, a combined effect of hardness and porosity were also accounted for the improvement of wear resistant properties in SS316L based MMCs with iron aluminide particle reinforcements. The improvement in the wear resistance of the alumina-based composites in the initial sliding conditions can be attributed to hardness of $\mathrm{Al}_{2} \mathrm{O}_{3}$ particles and the size of the particle in the matrix $(1 \mu \mathrm{m})$. The distribution of hard phase particles such as alumina in the composites, finer particle size results in smaller mean free path, which makes the composites homogeneous [10].

Though alumina addition had a beneficial effect in the matrix during initial sliding phases, this beneficial effect did not be sustain with increase in sliding distance. The alumina reinforced matrix is capable of withstanding wear under high loads only in initial sliding conditions. Vardavoulias et al 1996, working with P/M based austenitic stainless steels reported similar observations [11]. The presence of alumina particles in the SS316L matrix has a positive effect on the wear resistance by increasing the hardness of the matrix. In case of 10 and $20 \%$ alumina reinforcements, the hardness were recorded as $785 \mathrm{HV}_{0.10}$ and $910 \mathrm{HV}_{0.10}$, which are very much higher than the matrix hardness value of $400 \mathrm{HV}_{0.10}$. The higher hardness improves the overall strength of the matrix and this in turn, improves the wear properties. But, as the sliding progresses, due to weak interface bonding of alumina particles with the SS316L matrix, pull- out of alumina particles happens during wear (Fig.10).

Due to pull out of alumina, the support received by the matrix from the hard particles was lost during sliding. This creates a situation where the alumina particles are gradually being removed from the matrix, exposing the base SS316L matrix to severe wear. In addition, the pull-out alumina particles entrapped between the sliding pairs led to three body abrasion situations. Under this condition, wear damage in the matrix becomes severe leading to high wear rates. The damage due to pull-out leads to a) surface cracks and b) delamination of surface which are evident from Fig. 11. Also, alumina being thermodynamically stable and being non-metallic in properties, it cannot dissolve or react with the matrix during the sintering.

Hence, they are being retained in the matrix more or less in the original form. Therefore, the chemical bonding of the alumina particle with the base matrix does not actually exist. Although alumina has high thermal stability and high hardness, its poor chemical reactivity with the matrix prevents it from being strongly bonded within a ferrous matrix [12]. Large amounts of $\mathrm{Al}_{2} \mathrm{O}_{3}$ decrease the transverse rupture strength because, the ceramic particles act as crack initiators either by debonding at the particle /matrix interface or by cracking within particles. Hence, the only strengthening factor available for the matrix during the longer sliding distance was self strain hardening of SS316L. However, the benefit is not sufficient enough for the matrix in continuous wear situation and therefore higher wear rates were observed. Hence, pull-out of alumina and delamination are the proposed wear mechanisms for $\mathrm{Al}_{2} \mathrm{O}_{3}$ based $\mathrm{SS} 316 \mathrm{~L}$ MMCs.

The cumulative wear performance of the SS316L with and without 10 and $20 \%$ iron aluminide and with alumina particle reinforcements tested at 20 and $40 \mathrm{~N}$ load conditions under $2160,3240,4320$ and 6480 meters of sliding distances are presented in Fig.12. It is evident that iron aluminide particle reinforcement provided a beneficial effect on the wear properties of SS316L at long sliding distances by providing better support to the matrix. Though short term gains in wear resistance were evident from the alumina addition in SS316L matrix, however they last only for shorter sliding distances. 


\section{CONCLUSIONS}

In the present investigation, dry sliding wear of unreinforced and reinforced PM based SS316L with different volume fractions of iron aluminide intermetallic particles at different sliding distances was studied. Based on the tests conducted, the following conclusions are drawn:

1. Dry sliding wear properties improved significantly in SS316L MMCs with the addition of mechanically alloyed nano $\mathrm{Fe}_{3} \mathrm{Al}$ particles compared to sintered SS316L material without reinforcement. In addition, there is significant increase in wear resistance with the increase in volume fraction from $10 \%$ to $20 \% \mathrm{Fe}_{3} \mathrm{Al}$ in MMCs. Nano sized iron aluminide particles significantly reduce the porosity of the matrix and increase the hardness of the matrix.

2. Around $30-50 \%$ significant reduction in wear rate in longer sliding distance if $\mathrm{Fe}_{3} \mathrm{Al}$ was reinforced which signifies the role of $\mathrm{Fe}_{3} \mathrm{Al}$ particles in improving the wear resistance in SS316L matrix. SEM examination of worn surfaces indicates a combination of delamination, and mechanically mixed layer formation was proposed as wear mechanisms for $\mathrm{Fe}_{3} \mathrm{Al}$ based MMCs. Plowing, adhesion, MML formation during sliding and delamination were proposed wear mechanism for MMCs with $\mathrm{Fe}_{3} \mathrm{Al}$ particles.

3. Typical pull-out of alumina particles from the matrix during longer sliding distances, subsequent surface damage by pull-out hard alumina particles are accounted for increased wear rates observed in $\mathrm{Al}_{2} \mathrm{O}_{3}$ particles.

4. Comparing the wear properties between $\mathrm{Fe}_{3} \mathrm{Al}$ and $\mathrm{Al}_{2} \mathrm{O}_{3}$ particle reinforced MMCs during longer sliding distances, $\mathrm{Fe}_{3} \mathrm{Al}$ based MMCs performs better than $\mathrm{Al}_{2} \mathrm{O}_{3}$ MMCs.

\section{REFERENCES}

[1] ASM Hand Book, Vol.7, Powder Metal technologies and Applications, 1998, 861865.

[2] J.H.Westbrooke, Intermetallic Compounds ,Volume 2, Practice (591).

[3] D.E. Alman, J.A.Hawk, J.H. Tylczak, C.P. Dogan, R.D. Wilson, Wear ,251 (2001), 875- 883.

[4] J.S. Benjamine, Metall. Trans.,1,(1970),2943.

[5] Wolski K, Thevenot F, Le Coze J, Intermetallics, 4, (1996) ,299-307.

[6] Yong-Suk Kim, Yong-Hwan Kim, Materials Science and Engineering A ,258 (1998), 319-324.

[7] H.E. Maupin, R. D. Wilson and J. A. Hawk ,(1993),Wear, 162-164, 432-440.

[8] N.S. Stoloff, Mater. Sci. and Engg A ,(1998), 258, 1.

[9] Hsu K. L., T. M. Ahn and D. A. Rigney (1980) Friction, wear and microstructure of unlubricated austenitic stainless steels, Wear, 60, 87.

[10] Zum- Gahr,(1998) Tribology International, 31,10, 587-596.

[11] Vardavoulias M., M. Jeandin, F. Valasco and J. M. Torralba, Tribology International, (1996),29, 6, 499-506.

[12] Queeney R. A. (1990) Advances in Powder Metallurgy and Particulate Materials, Vol . 8, MPIF, Princeteon, USA, p. 89. 


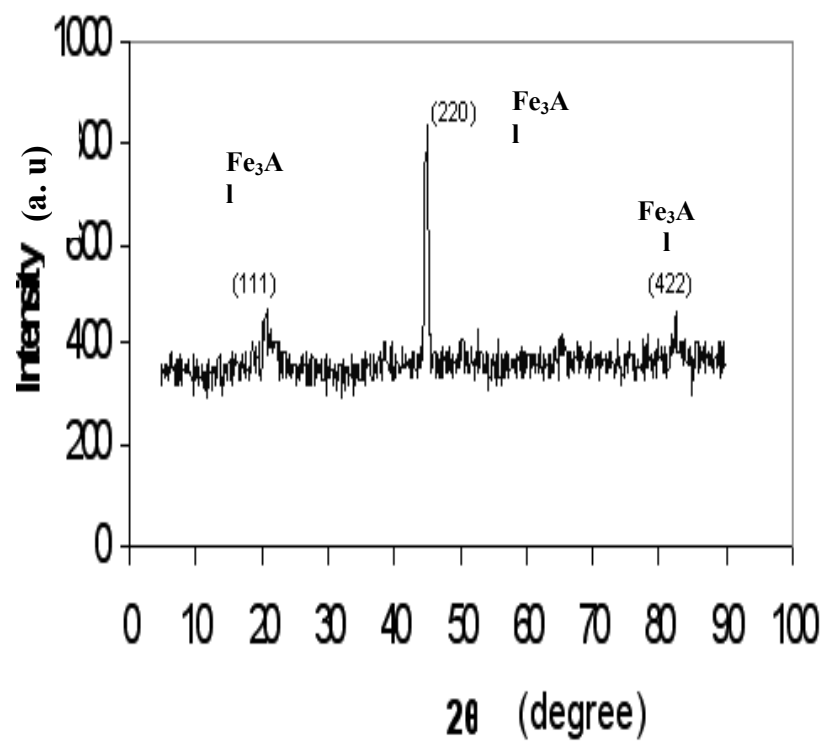

$\mathrm{Cu} \mathrm{K}_{\alpha}$ radiation

Fig.1: X-ray diffraction patterns of mechanically alloyed iron aluminide powders
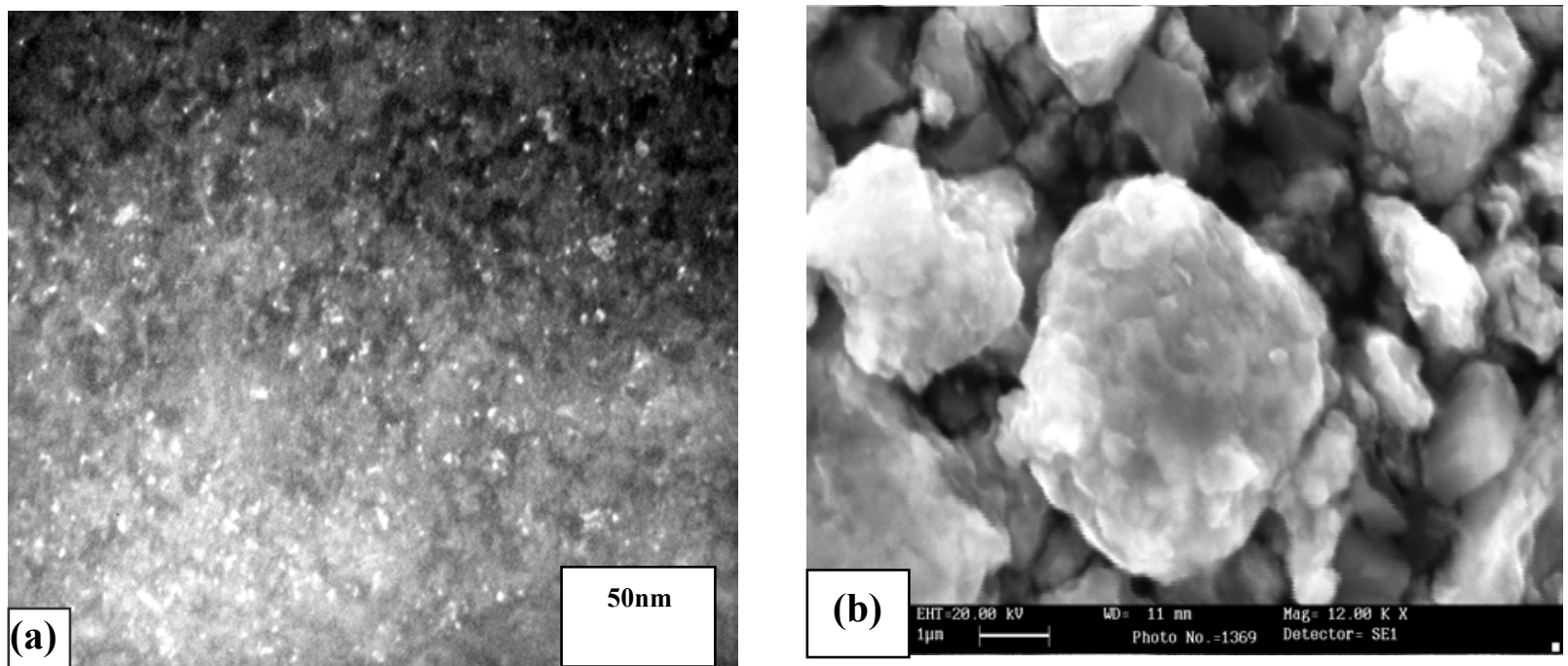

Fig. 2 TEM and SEM micrograph of mechanically alloyed iron aluminide powders. 


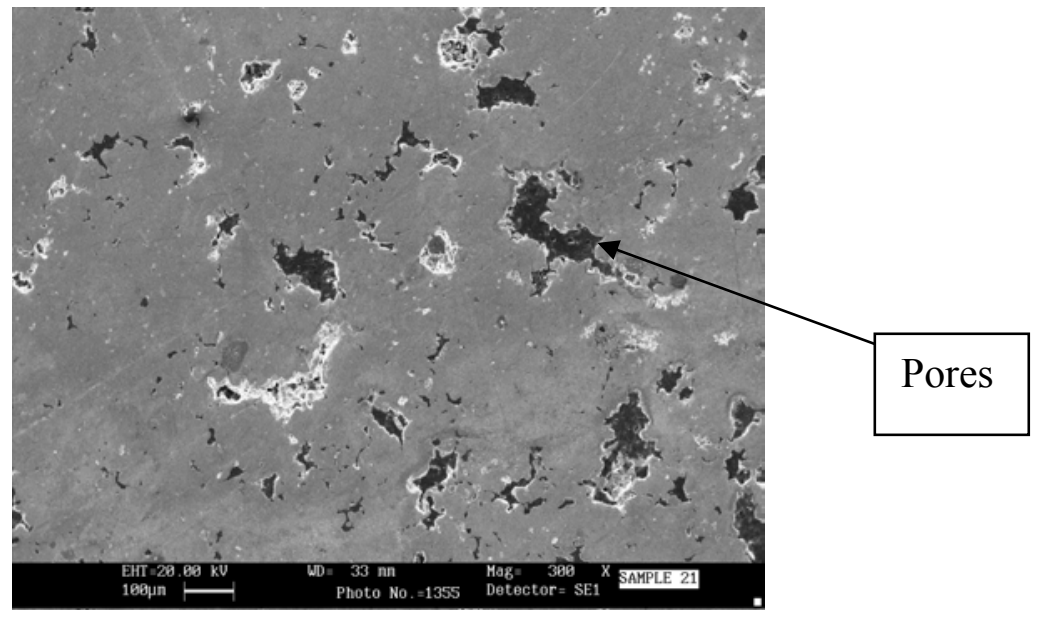

Fig.3 SEM micrograph of SS316L matrix without particle reinforcement

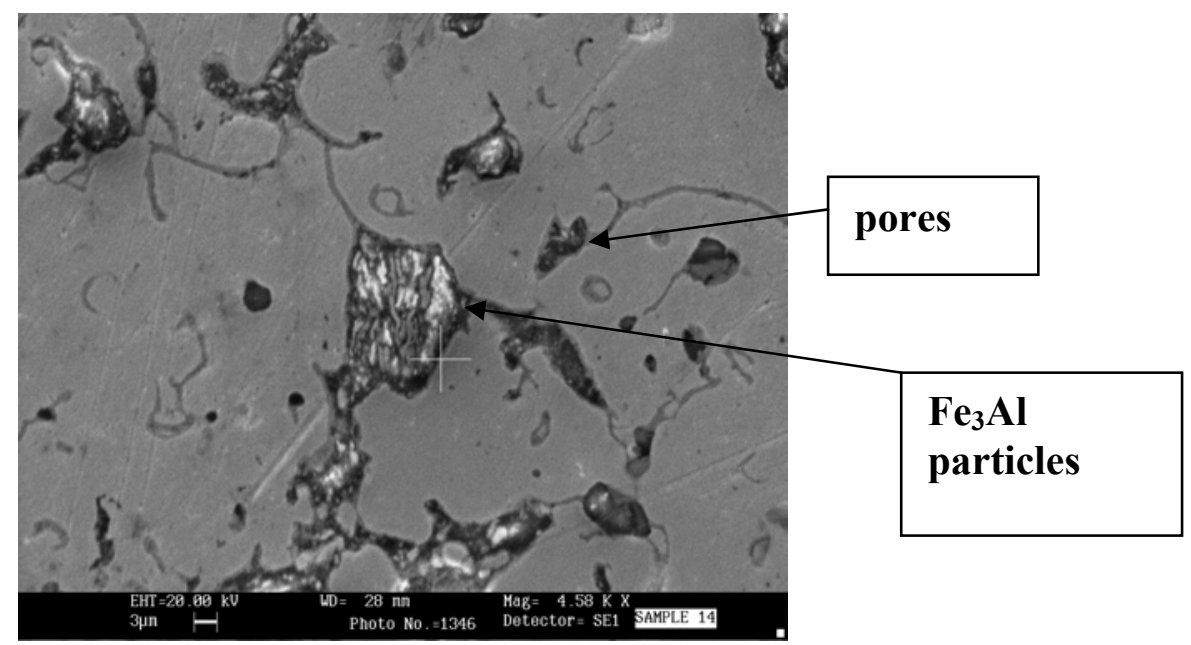

Fig.4 SEM micrograph of SS316L matrix with $20 \%$ iron aluminide showing $\mathrm{Fe}_{3} \mathrm{Al}$ particles in the matrix particle reinforcement. 


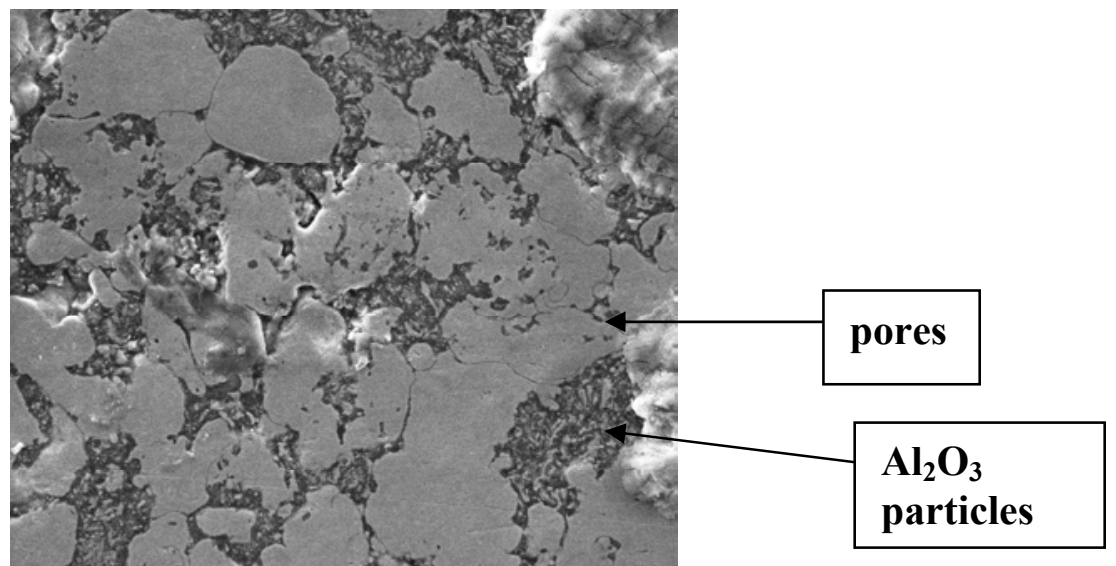

Fig.5 SEM micrograph of SS316L matrix with $20 \% \mathrm{Al}_{2} \mathrm{O}_{3}$ reinforcement

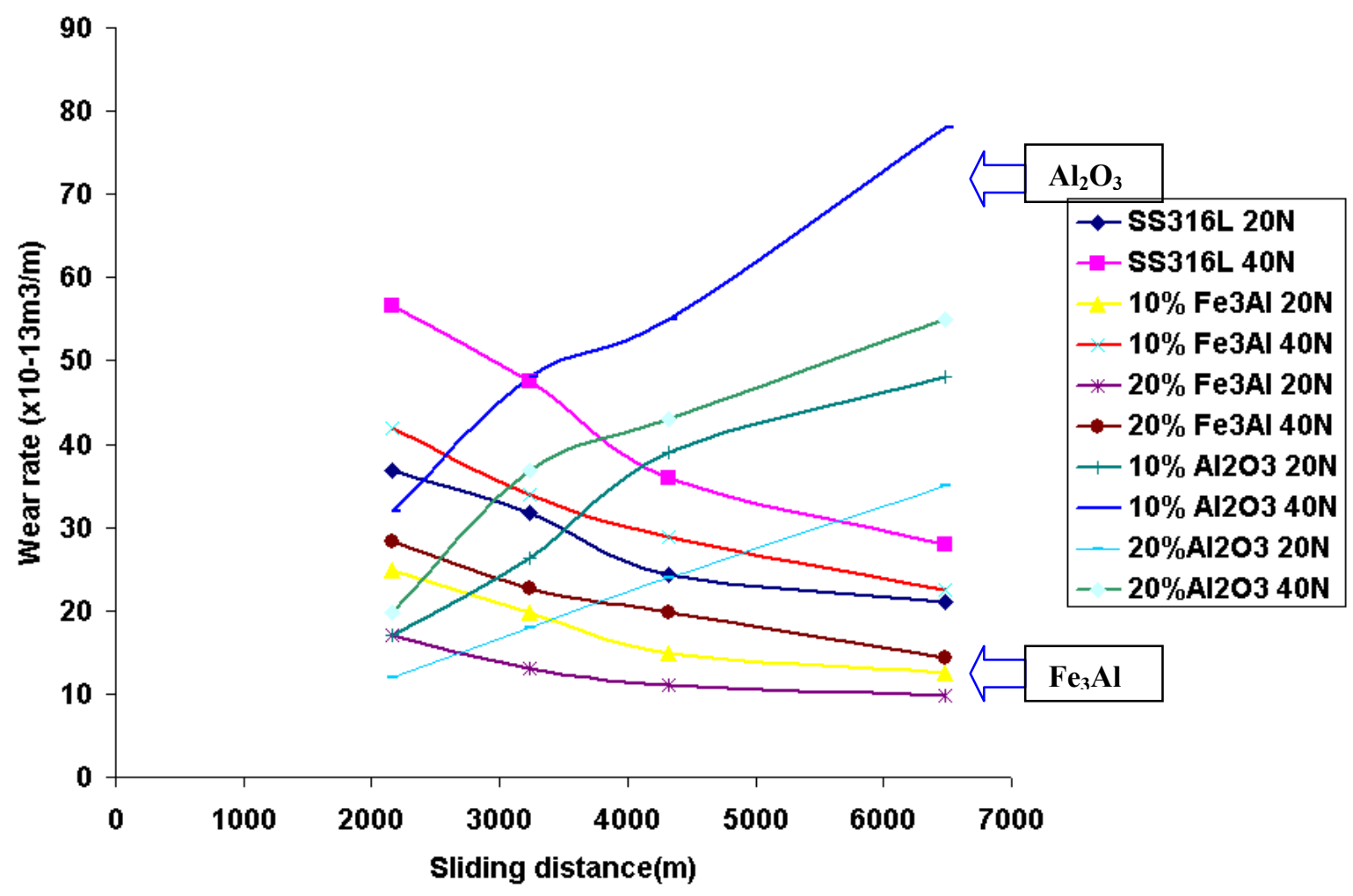

Fig. 6 Wear rate comparison of MMCs with SS316L and with 10 and 20\% $\mathrm{Fe}_{3} \mathrm{Al}$ and $\mathrm{Al}_{2} \mathrm{O}_{3}$ at $20 \mathrm{~N}$ and $40 \mathrm{~N}$. 


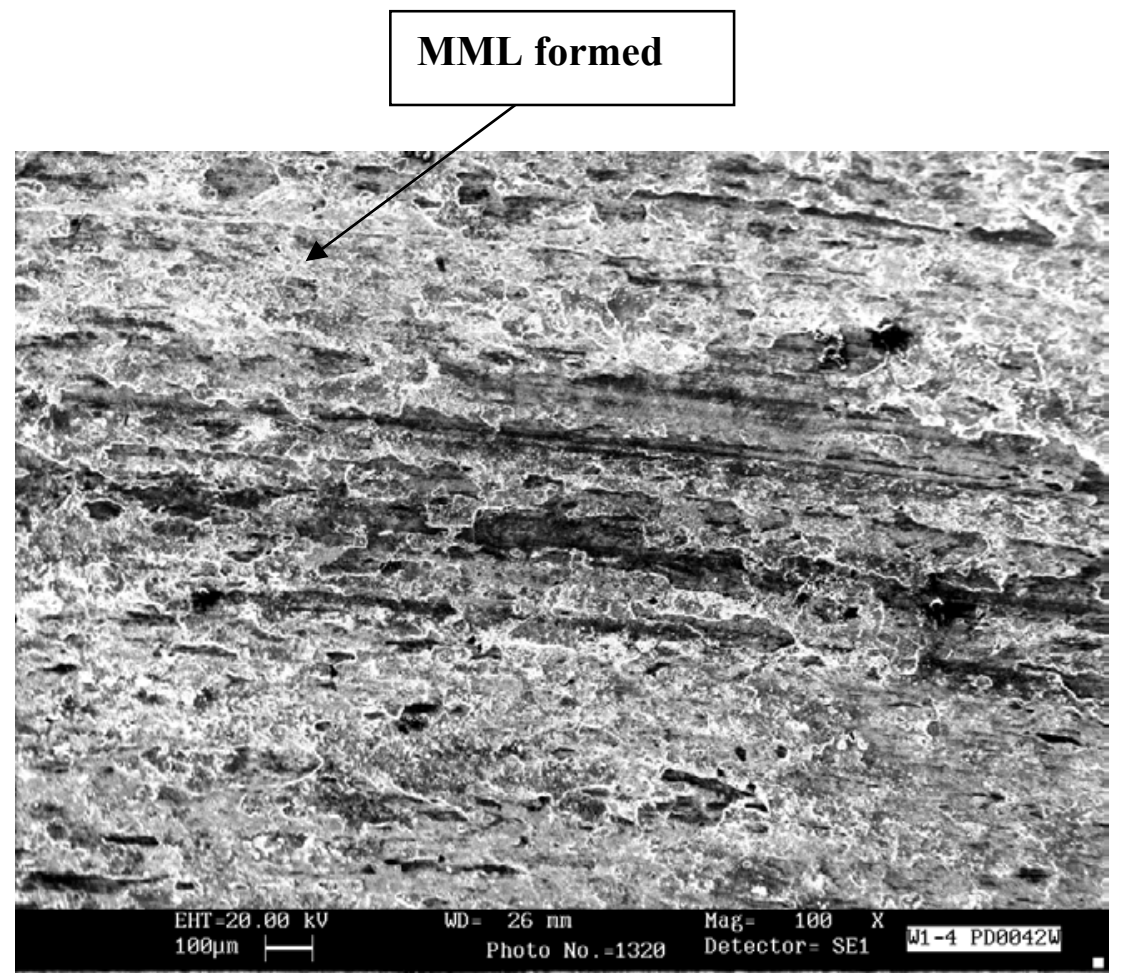

Fig. 7 SEM micrographs of SS316L with $10 \% \mathrm{Fe}_{3} \mathrm{Al}$ at $40 \mathrm{~N} \& 6480 \mathrm{~m}$

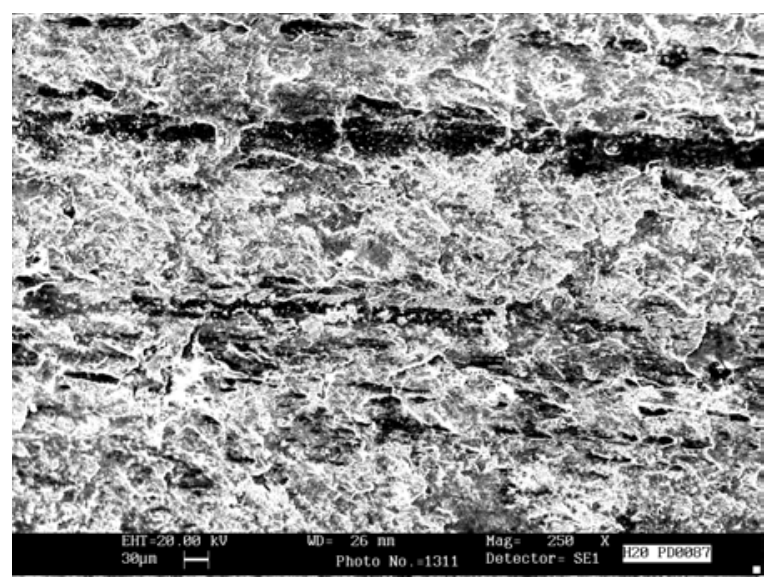

Fig. 8 SEM micrograph of SS316L with $20 \% \mathrm{Fe}_{3} \mathrm{Al}$ matrix at $6480 \mathrm{M}$ at $40 \mathrm{~N}$. 


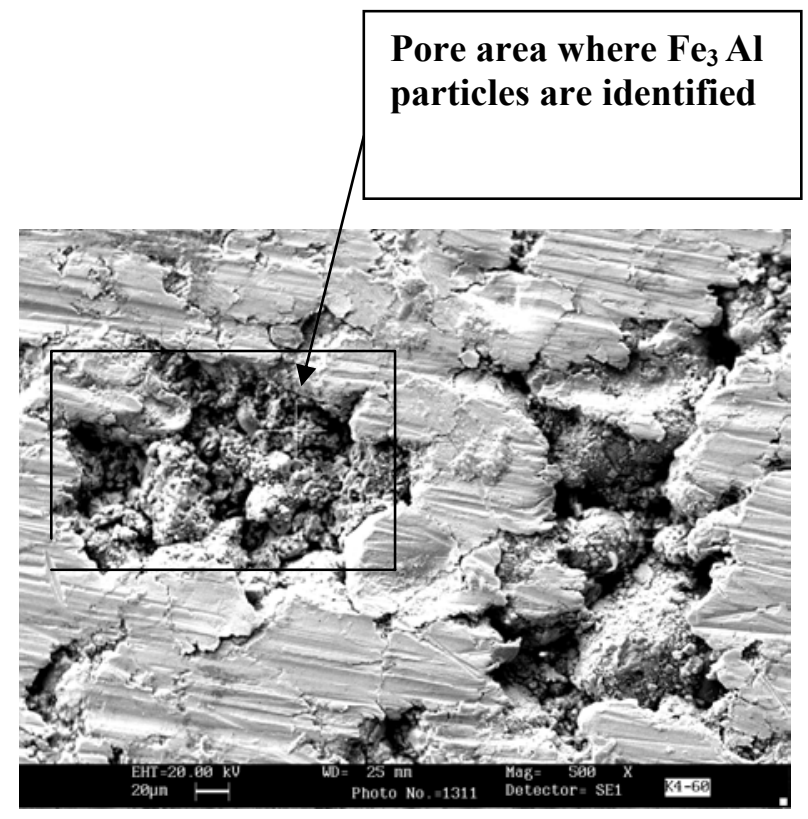

Fig.9 SEM micrograph of a pore occupied by iron aluminide particles

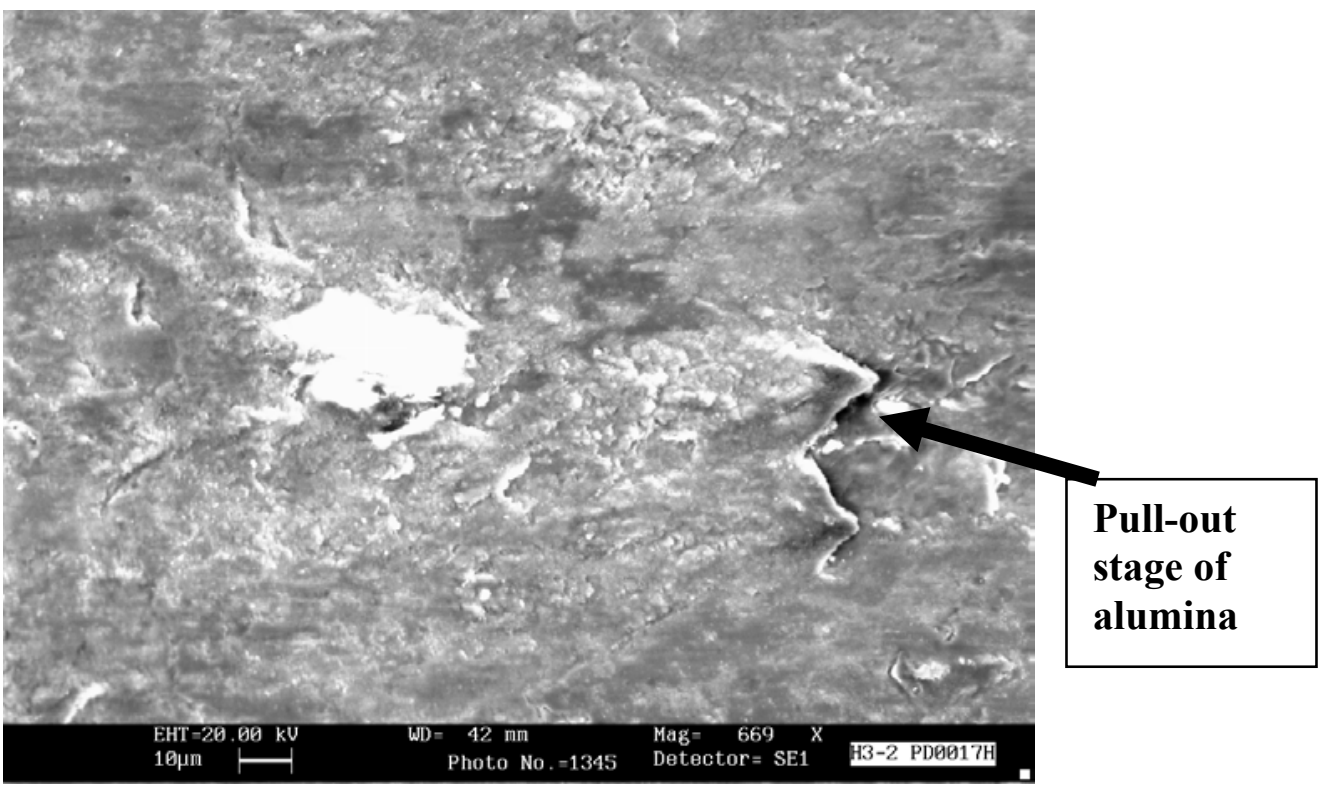

Fig.10 SEM micrographs showing the pull -out stage of alumina from SS316L matrix 


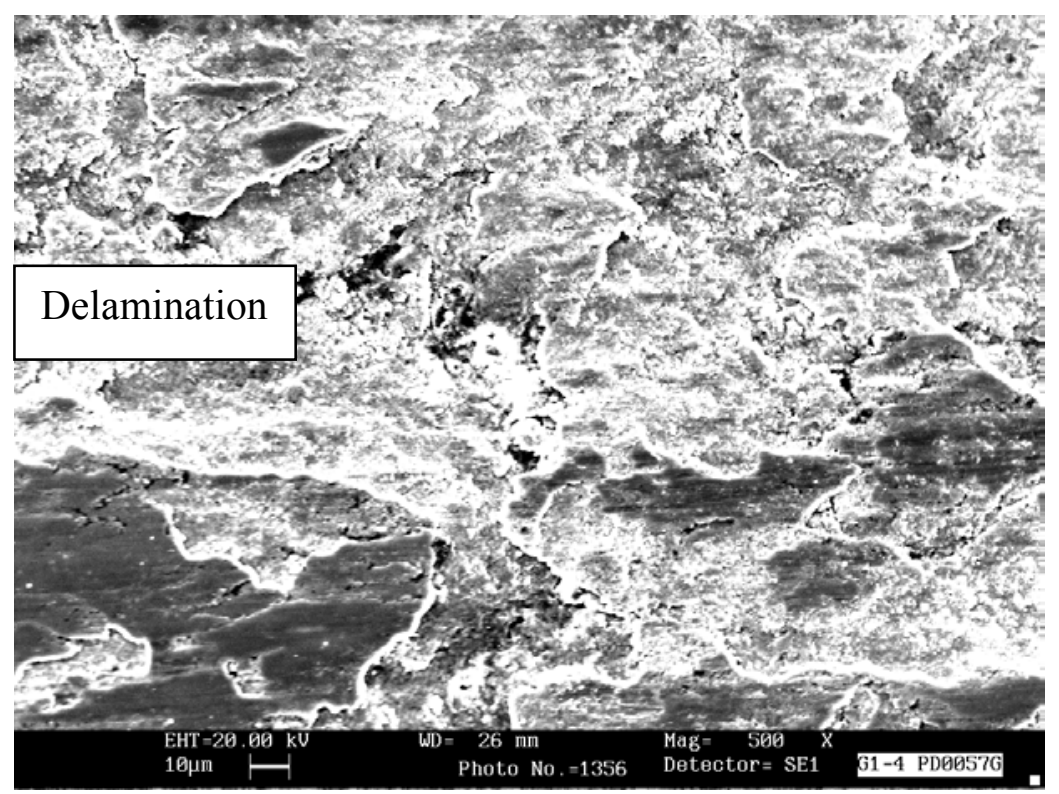

Fig.11 SEM micrographs showing delamination in $10 \% \mathrm{Al}_{2} \mathrm{O}_{3}$ reinforced SS316L matrix

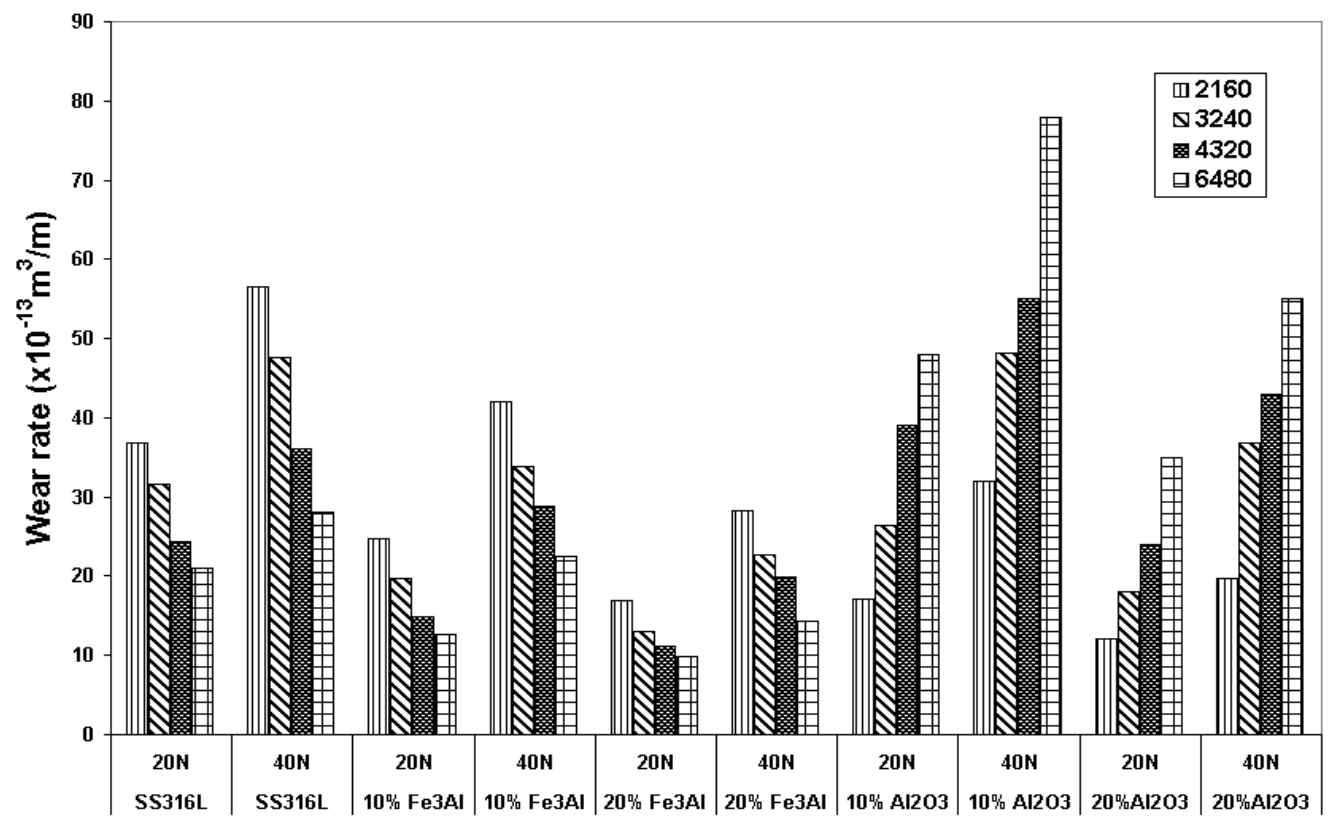

Matrix composition

Fig. 12. Wear rate comparison among SS316L, iron aluminide and alumina reinforced MMCs. 